\title{
Arsenic speciation in Chinese Herbal Medicines and human health implication for inorganic arsenic
}

\author{
Xiao-Juan Liu a, Quan-Li Zhao ${ }^{\text {a }}$, Guo-Xin Sun ${ }^{\text {b }}$, Paul Williams ${ }^{\text {b,c }}$, Xiu-Jun Lu ${ }^{\text {d }}$, Jing-Zhu Cai ${ }^{\text {, }}$ \\ Wen-Ju Liu ${ }^{\mathrm{a}, *}$ \\ ${ }^{a}$ College of Resources and Environmental Science, Hebei Agricultural University, Baoding, 2596 Lekainan Street, Hebei Province 071000, China \\ ${ }^{\mathrm{b}}$ Research Center for Eco-Environmental Sciences, The Chinese Academy of Sciences, Beijing 100085, China \\ ${ }^{\mathrm{c}}$ Lancaster Environment Centre, Lancaster University, Lancaster LA1 4YQ UK \\ ${ }^{\mathrm{d}}$ College of Plant Protection, Hebei Agricultural University, Baoding, Hebei Province 071000, China \\ ${ }^{\mathrm{e}}$ College of Agronomy, Hebei Agricultural University, Baoding, Hebei Province 071000, China
}

\section{A R T I C L E I N F O}

\section{Article history:}

Received 17 June 2012

Received in revised form 31 August 2012

Accepted 8 September 2012

\section{Keywords:}

Arsenic speciation

Chinese Herbal Medicines (CHMs)

Inorganic arsenic

\begin{abstract}
A B S T R A C T
Rice and drinking water are recognized as the dominant sources of arsenic (As) for human intake, while little is known about As accumulation and speciation in Chinese Herbal Medicines (CHMs), which have been available for many hundreds of years for the treatment of diseases in both eastern and western cultures. Inorganic arsenic was the predominant species in all of CHMs samples. The levels of inorganic arsenic in CHMs from fields and markets or pharmacies ranged from 63 to $550 \mathrm{ng} / \mathrm{g}$ with a mean of $208 \mathrm{ng} / \mathrm{g}$ and 94 to $8683 \mathrm{ng} / \mathrm{g}$ with a mean of $1092 \mathrm{ng} / \mathrm{g}$, respectively. The highest concentration was found in the Chrysanthemum from pharmacies. It indicates that the risk of inorganic As in CHMs to human health is higher in medicines from markets or pharmacies than that collected directly from fields. Some CHMs may make a considerable contribution to the human intake of inorganic arsenic.
\end{abstract}

(c) 2012 Elsevier Ltd. All rights reserved.

\section{Introduction}

Herbal or medicinal plant products in various forms have been available for many hundreds of years for treatment of diseases in both Eastern and Western cultures (Chan, 2003). A survey indicated that about $70-80 \%$ of the world populations, particularly in the developing countries, rely on non-conventional medicine mainly from herbal sources in their primary healthcare reported by WHO (Akerele, 1993; Chan, 2003). Chinese Herbal Medicines and their manufactured products recorded in the Chinese Pharmacopoeia have been approved for safe use and have been widely consumed for thousands of years as home remedies or for prevention and treatment of diseases in China (Chan, 2003; Chinese Pharmacopoeia Commission, 2005). Such increase in popularity has also brought concerns and fears over the adverse effects of herbal medicines, thus the quality, efficacy and safety of the products from herbal and natural sources available in the market should have been proven. Therefore, contamination or adulteration of CHMs with heavy metals such as lead, mercury, cadmium or arsenic has attracted much attention (Au and Reddy, 2000; Koh and

\footnotetext{
* Corresponding author.

E-mail addresses: liuwj@hebau.edu.cn, wenjuliu71@hotmail.com (W.-J. Liu).
}

Woo, 2000), especially arsenic contamination through natural and anthropogenic pathways (Koch et al., 2007; Liu et al., 2010a,b). There are concerns that CHMs can accumulate As from growth environments and conditions, such as soil/plant uptake, irrigation water and from atmospheric deposition, and conditions during dryness, storage, transport and manufacturing processes (Chan, 2003; Liang et al., 1998; Liu et al., 2010a). China has a maximum contaminant concentration (Green Standard of Medicinal Plants and Preparations for Foreign Trade and Economy in China) for arsenic in CHMs of $2.0 \mathrm{mg} / \mathrm{kg}$. Some investigations of total arsenic in CHMs from both domestic and foreign markets have illustrated that total arsenic concentrations in some CHMs samples exceeded this legislative standard (Cooper et al., 2007; Liu et al., 2010a).

Arsenic is a ubiquitous element in the natural environment. The International Agency for Research on Cancer (IARC) regards inorganic arsenic as a carcinogen with a linear dose response for chronic exposure (IARC (International Agency for Research on Cancer), 1973; NRC (National Research Council), 2001). Because inorganic As is considered to be more toxic than methylated species - MMAV and DMAV (Marin et al., 1992; NRC (National Research Council), 2001; Schoof et al., 1999), the assessment of human health risk associated with As in edible plants or foodstuffs mainly depends on the concentrations of inorganic arsenic(Muñoz et al., 2002; Schoof et al., 1999; Tsuji et al., 2007). Moreover, Food and 
Agriculture Organization/World Health Organization (FAO/WHO) has a provisional tolerable weekly intake (PTWI) for inorganic arsenic of $15 \mu \mathrm{g} / \mathrm{kg}$ bodyweight $(2.1 \mu \mathrm{g} / \mathrm{kg}$ bodyweight (b.w.)/d) (FAO/WHO (Food and Agriculture Organization/World Health Organization), 1993). Allowable Daily Intake (ADI) of inorganic As for one person with $60 \mathrm{~kg}$ bodyweight would be $126 \mathrm{ng} / \mathrm{g}$. However, the EFSA (European Food Safety Authority) Panel on Contaminants in the Food Chain (CONTAM Panel) suggested that PTWI of $15 \mu \mathrm{g} / \mathrm{kg}$ b.w. established by the Joint FAO/WHO Expert Committee on Food Additives (JECFA) is no longer appropriate as data had shown that inorganic arsenic causing cancer of the lung, urinary bladder and skin had been reported at exposures lower than those reviewed by the JECFA. CONTAM Panel assessed the risks of arsenic in food to human health. The inorganic arsenic exposure from food and water across 19 European countries had been estimated to range from 0.13 to $0.56 \mu \mathrm{g} / \mathrm{kg}$ bodyweight (b.w.) per day for average consumers and from 0.37 to $1.22 \mu \mathrm{g} / \mathrm{kg}$ b.w. per day for 95th percentile consumers(European Food Safety Authority (EFSA), 2009). Chinese Government, considering the adverse effects of inorganic As on human health, had issued the maximum levels of inorganic arsenic in foods in GB2762-2005, such as rice flour (150 ng/g), wheat flour (100 ng/g), non-staple cereals (200 ng/g) and vegetables (50 ng/ g)(China Food Standard Agency, 2005).

Most recent studies have focused on the total As levels in CHMs, and little information is available on arsenic species in CHMs and the human health implications of inorganic As in CHMs. More research is therefore needed into human intakes of inorganic arsenic in CHMs and its risk to health. In addition, Chinese Government had put more emphasis on the effects of inorganic As on human health and issued the regulatory standards for inorganic arsenic in foods in GB2762-2005, but they have not well built up the related certified reference materials (CRMs) and developed the protocols for analysis of inorganic arsenic in terrestrial edible plants, especially Chinese Herbal Medicines. Therefore, the one objective of this study was to screen a suitable extraction method for As species in CHMs. In general, arsenic in CHMs comes from growth environments and conditions, or CHMs accumulate arsenic under conditions during dryness, storage, transport and manufacturing processes. For this reason, some samples were directly collected from field to represent pure/unprocessed plant materials with un-impacted As species. We also collected CHMs samples from markets or pharmacies, considering the processes could impact on the As species in the medicines. Arsenic speciation in CHMs taken directly from fields and from markets or pharmacies was extracted using that selected method and analyzed by HPLCICP-MS. The risk to human health of inorganic arsenic in CHMs has also been examined.

\section{Materials and methods}

\subsection{Survey}

An-guo city in Hebei province has been well known for cultivating and processing herbal medicines in China for hundreds of years. According to the local cultivated species, planting areas and locations, 12 typical herb medicine species were selected and samples were directly collected from field or purchased from markets or pharmacies ( $n=197$ in total). Based on a preliminary survey of total As in CHMs (Liu et al., 2010a), a part of samples $(n=65)$ with high levels of total As in CHMs were selected to explore As speciation in this study.

In general, the roots of some herb plants can be used as medicines only, which were collected as samples in this study, including Indigowoad Root (Isatis indigotica; Banlangen in Chinese), Large-head Atractylodes Rh (Atractylodes macrocephala; Baizhu in Chinese), Danshen (Salvia miltiorrhiza), Radix Saposhnikoviae (Saposhnikovia divaricata; Fangfeng in Chinese), Radix Astragali(Astragalus membranaceus, Huangqi in Chinese), Tatarian Aster (Aster tataricus; Ziwan in Chinese), Rhizoma anemarrhenae (Anemarrhena asphodeloides; Zhimu in Chinese), Radix Trichosanthis (Trichosanthes kirilowii; Tianhuafen in Chinese). Except for herbal roots, other organs of herbs could be medicines, such as shoots of Schizonepeta
(Schizonepeta tenuifolia; Jingjie in Chinese) and Indigowoad Leaf (Isatis indigotica Fort., Daqingye in Chinese), and fruits of Trichosanthis (Trichosanthes kirilowii: Gualou in Chinese) and flowers of Chrysanthemum(Dendranthema morifolium; Juhua in Chinese and well known as tea as well in eastern and western countries) Both root and leaf of Isatisin digotica and both root and fruit of Trichosanthes kirilowii are used as medicines in general.

\subsection{Samples preparation}

All samples were washed with ultrapure water (18.2 M $\Omega$ ), and then were ovendried at $65^{\circ} \mathrm{C}$ until a constant weight was reached. The dry samples were powdered using a stainless-steel ball-mill. All samples were stored in desiccators at room temperature before extraction.

\subsection{Chemicals}

AnalaR Nitric acid $\left(\mathrm{HNO}_{3}\right)(70 \%)$ and hydrogen peroxide $\left(\mathrm{H}_{2} \mathrm{O}_{2}\right)(30 \%)$ used were reagent grade and were obtained from Beijingchemical works; Trifluoroacetic acid (TFA) $\left(\mathrm{C}_{2} \mathrm{HF}_{3} \mathrm{O}_{2}\right)(99 \%)$ were obtained from Sigma-Aldrich. Sodium arsenate $\left(\mathrm{Na}_{3} \mathrm{AsO}_{4} \cdot 12 \mathrm{H}_{2} \mathrm{O}\right)$ was purchased from Chemical Reagent Factory of Union in Beijing and sodium arsenite $\left(\mathrm{NaAsO}_{2}\right)$ was purchased from Merck (Germany). Methylarsonic acid $\left(\mathrm{MMA}^{\mathrm{V}}\right)$ and dimethylarsinic acid $\left(\mathrm{DMA}^{\mathrm{V}}\right)$ were purchased from PA (USA) Indium (In), the internal standard in ICP-MS, was a high purity stock supplied from Agilent (USA). The HPLC mobile phase was prepared using diammonium hydrophosphate $\left(\left(\mathrm{NH}_{4}\right)_{2} \mathrm{HPO}_{4}\right)$ and ammonium nitrate $\left(\mathrm{NH}_{4} \mathrm{NO}_{3}\right)$, which all were analytical reagent (AR) from Fucheng Chemicals (Tianjin) and Shantou Chemicals (Guangdong), respectively. The certified reference material (CRM) of rice flour (GBW10010) from the National Research Center for Standard Materials in China was used to validate the analyses. Ultrapure water $(18.2 \mathrm{M} \Omega$ ) in preparation for solution was produced by Milli-Q Element system from Millipore (USA).

\subsection{Arsenic speciation extraction}

Method screening: to obtain the suitable extraction method of arsenic speciation in CHMs, four methods to extract As species were evaluated in this study according to TFA extraction method from Heitkemper et al. (2001) and microwave extraction with $1 \% \mathrm{HNO}_{3}$ solution in Zhu et al. (2008). No certified reference material (CRM) for arsenic speciation in herbal medicine, the CRM of Chinese rice flour GBW10010, arsenic speciation published in Zhu et al. (2008), was used to validate analysis. We consider that the herbal medicine is normally roots or shoots different from rice flour, so Panax notoginseng (Sanqi in Chinese), one of herbal medicines, was run for arsenic speciation extraction with rice CRM. Arsenic speciation in rice flour CRM and herbal medicine sample Panax notoginseng were extracted by the following methods:

1 Microwave method for extracting arsenic species: Ultra-pure water, $1 \% \mathrm{HNO}_{3}, 1 \%$ $\mathrm{HNO}_{3}+1 \% \mathrm{H}_{2} \mathrm{O}_{2}$ (Table 1 ). The CRM and $0.2000 \mathrm{~g}$ of Panax notoginseng were weighed into $50 \mathrm{ml}$ polypropylene centrifuge tubes and $10 \mathrm{ml}$ of solutions was added, respectively. Covered centrifuge tubes were allowed to stand overnight at room temperature. All tubes were randomized, heated in a microwave accelerated reaction system (CEM Microwave Technology Ltd, USA) using three temperature steps: (1) maintained samples at $55^{\circ} \mathrm{C}$ for $10 \mathrm{~min}$; (2) at $75^{\circ} \mathrm{C}$ for $10 \mathrm{~min}$; (3) at $95^{\circ} \mathrm{C}$ for $30 \mathrm{~min}$. And each step ramped to temperature over a 5 min period.

2 Extraction with 2M TFA (Trifluoroacetic acid). TFA has been commonly used to extract As species in rice plant samples (Abedin et al., 2002; Liu et al., 2006; Williams et al., 2005). The sample $(0.2000 \mathrm{~g})$ was weighed into the quartz glass digestion tubes, and steeped in $2 \mathrm{ml}$ of $2 \mathrm{~mol} / \mathrm{l}$ TFA solution. The tubes were then left overnight at room temperature, followed by digestion heating block at $100^{\circ} \mathrm{C}$ for $5 \mathrm{~h}$ until the solution evaporated to dryness. If not, the temperature was elevated to $160^{\circ} \mathrm{C}$ to dry the content. When the tubes were cooled down, the residues and solution were vortexed by ultra-pure water to $10 \mathrm{ml}$. Samples were then centrifuged at $7000 \mathrm{rpm}$ for $8 \mathrm{~min}$, and the supernatant was collected and passed through a $0.45 \mu \mathrm{m} \times 13 \mathrm{~mm}$ nylon filter.

Based on our findings, microwave extraction with $1 \% \mathrm{HNO}_{3}$ solution was the most suitable method for arsenic species extraction in CHMs (Table 1). Therefore, milled subsamples of $\mathrm{CHMs}$ were extracted with $1 \% \mathrm{HNO}_{3}$ using the microwaveoven system.

\subsection{Arsenic speciation determination}

Arsenic speciation analysis was performed using high performance liquid chromatography inductively coupled plasma-mass spectrometry (HPLC-ICP-MS Agilent 1200 series and Agilent ICP-MS7500, Agilent Technologies, USA.) connected to a PRP-X100 $10 \mu \mathrm{m}$ anion-exchange column $(250 \times 4.1 \mathrm{~mm})$. The injection volume of the sample was $20 \mu \mathrm{l}$. The mobile phase consisted of pre-filtered $(0.45 \mu \mathrm{m}) 5 \mathrm{mM}$ $\mathrm{NH}_{4} \mathrm{NO}_{3}$ and $5 \mathrm{mM}\left(\mathrm{NH}_{4}\right)_{2} \mathrm{HPO}_{4}$, adjusted to $\mathrm{pH} 6.2\left(\mathrm{HNO}_{3}\right)$ with flow rate at $1.0 \mathrm{ml}$ 
Table 1

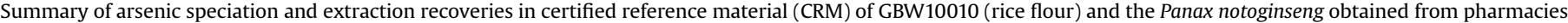
using four extraction methods (Means $\pm \mathrm{SE}, n=3$ ).

\begin{tabular}{|c|c|c|c|c|c|c|c|c|}
\hline \multirow[t]{2}{*}{ CRM and sample } & \multirow[t]{2}{*}{ As species extraction } & \multirow[t]{2}{*}{ Total As (ng/g) } & \multicolumn{5}{|c|}{ As species (ng/g) } & \multirow[t]{2}{*}{ Recovery (\%) } \\
\hline & & & $\mathrm{As}^{\mathrm{III}}$ & $\mathrm{As}^{\mathrm{V}}$ & $\mathrm{DMA}^{\mathrm{V}}$ & $\mathrm{MMA}^{\mathrm{V}}$ & Species sum & \\
\hline \multirow[t]{4}{*}{ GBW10010 } & Ultra-pure water & 102 & $24 \pm 1$ & $17 \pm 0.5$ & $11 \pm 0.3$ & $0.6 \pm 0.2$ & $52 \pm 1$ & $51 \pm 1$ \\
\hline & $1 \% \mathrm{HNO}_{3}$ & 102 & $68 \pm 7$ & $18 \pm 3$ & $27 \pm 1$ & $3 \pm 0.8$ & $117 \pm 11$ & $115 \pm 11$ \\
\hline & $1 \% \mathrm{HNO}_{3}+1 \% \mathrm{H}_{2} \mathrm{O}_{2}$ & 102 & $13 \pm 0.4$ & $80 \pm 7$ & $27 \pm 2$ & $5 \pm 2$ & $130 \pm 13$ & $128 \pm 12$ \\
\hline & $2 \mathrm{~mol} / \mathrm{l} \mathrm{TFA}$ & 102 & $81 \pm 1$ & - & $6 \pm 2$ & - & $86 \pm 2$ & $84 \pm 1$ \\
\hline \multirow[t]{4}{*}{ Panax notoginseng } & Ultra-pure water ${ }^{\mathrm{b}}$ & 5985 & $374 \pm 4$ & $1744 \pm 20$ & $84 \pm 5$ & $1608 \pm 4$ & $3828 \pm 22$ & $64 \pm 0$ \\
\hline & $1 \% \mathrm{HNO}_{3}{ }^{\mathrm{c}}$ & 5985 & $685 \pm 19$ & $2729 \pm 46$ & $77 \pm 0$ & $1455 \pm 47$ & $4997 \pm 30$ & $83 \pm 0$ \\
\hline & $1 \% \mathrm{HNO}_{3}+1 \% \mathrm{H}_{2} \mathrm{O}_{2}$ & 5985 & $129 \pm 4$ & $2777 \pm 49$ & $104 \pm 12$ & $1699 \pm 5$ & $4709 \pm 44$ & $79 \pm 1$ \\
\hline & $2 \mathrm{~mol} / 1 \mathrm{TFA}^{\mathrm{d}}$ & 5985 & $2976 \pm 96$ & $236 \pm 39$ & $79 \pm 1$ & $1312 \pm 38$ & $4410 \pm 71$ & $74 \pm 1$ \\
\hline
\end{tabular}

${ }^{\text {a }}$ Recovery $=$ (species sum/total As)* 100 .

b Contained an unidentified As species at $20 \mathrm{ng} / \mathrm{g}$.

c Contained an unidentified As species at $42 \mathrm{ng} / \mathrm{g}$.

d Contained an unidentified As species at $122 \mathrm{ng} / \mathrm{g}$.

min. Retention time of peaks were identified by mixed arsenic speciation standards (10 $\mu \mathrm{g}$ As/l of arsenite, arsenate, dimethylarsinic acid $\left(\mathrm{DMA}^{\mathrm{V}}\right.$ ) and monomethylarsonic acid $\left(\mathrm{MMA}^{\mathrm{V}}\right)$ ). Arsenic species were quantified by external calibration with $\mathrm{DMA}^{\mathrm{V}}$ standard solutions $(0,5,10,15$, and $20 \mu \mathrm{g}$ of $\mathrm{As} / \mathrm{l})$. All data was normalized with the In-internal standard.

\subsection{Total digestion and determination of arsenic}

For total As concentration in CHMs, milled subsamples (about $0.2 \mathrm{~g}$ ) were weighted into a $50 \mathrm{ml}$ covered polypropylene centrifuge tubes and $2 \mathrm{ml}$ of concentrated $\mathrm{HNO}_{3}$ was added. The tubes were left overnight at room temperature and then heated in a microwave using the same temperature program as documented for As speciation extractions and finally made up to the volume of $25 \mathrm{ml}$ with ultra-pure water. Hydride generation and an atomic fluorescence spectrometry (AFS-2202E, Beijing Haiguang Analytical Instrument Co., Beijing, China) and inductively coupled plasma mass spectrometry (ICP-MS; Agilent 7500, Agilent Technologies, USA) were used in the As measurement. CRM and blanks were run during digestion for data quality controls.

\subsection{Speciation quality control}

To check the stability of arsenic species in $1 \% \mathrm{HNO}_{3}$ solution, four blank spikes with $10 \mu \mathrm{g} \mathrm{As} / \mathrm{l}$ of arsenite, arsenate, $\mathrm{DMA}^{\mathrm{V}}$ and $\mathrm{MMA}^{\mathrm{V}}$, respectively were taken in triplicate and then extracted in the microwave oven. Arsenic species in extract solutions were analyzed by HPLC-ICP-MS. The recoveries for the blank spikes of arsenite, arsenate, $\mathrm{DMA}^{\mathrm{V}}$, and $\mathrm{MMA}^{\mathrm{V}}$ using $1 \% \mathrm{HNO}_{3}$ were $92 \pm 2.2 \%, 99 \pm 0.4 \%$, $118 \pm 0.5 \%, 123 \pm 0.3 \%$, respectively. The mean limits of detection (LOD) for arsenite, arsenate, $\mathrm{DMA}^{\mathrm{V}}$, and MMA ${ }^{\mathrm{V}}$ by HPLC-ICPMS were $0.065,0.080,0.079,0.065 \mathrm{ng} / \mathrm{g}$.

\subsection{Statistical analysis}

Statistical analyses were undertaken using Origin Pro8.0 for graphic analysis and using SPSS 18.0 for ANOVA data analysis.

\section{Results and discussion}

\subsection{Recoveries of As Speciation extractions}

The recoveries of arsenic species extracted from rice CRM (GBW10010) or herbal medicine Panax notoginseng were different for the four extract solutions (Table 1). In general, the recoveries from rice CRM (GBW10010) were higher than those from Panax notoginseng according to the different extraction solutions. The reasonable explanation is that rice CRM is grain flour and Panax notoginseng is powder of roots. For ultra-pure water extraction, whether rice CRM (GBW10010) or herbal medicine Panax notoginseng, recoveries were the lowest, accounting for $51 \%$ and $64 \%$, respectively, compared to other extraction solutions. The higher recovery of As species from rice CRM extracted by $1 \% \mathrm{HNO}_{3}+1 \%$ $\mathrm{H}_{2} \mathrm{O}_{2}(128 \%)$ was probably because of a low concentration of arsenic in this CRM (Zhao et al., 2010). Better and stable recoveries from TFA extraction were observed in Table 1, 84\% for rice CRM and $74 \%$ for the herbal medicine sample, but TFA can reduce arsenate to arsenite during extraction. Much higher concentrations of As ${ }^{\text {III }}$ were observed in TFA extraction compared to others. Therefore, many reports just presented the combined concentration of inorganic arsenic composed of $\mathrm{As}^{\mathrm{III}}$ and $\mathrm{As}^{\mathrm{V}}$ (Abedin et al., 2002; Ackerman et al., 2005; Heitkemper et al., 2001; Liu et al., 2006; Smith et al., 2008, 2006; Vela and Heitkemper, 2004; Williams et al., 2005). The extract solution $1 \% \mathrm{HNO}_{3}$ has been used widely to extract arsenic species from plant tissue samples, especially for rice flour (Raab et al., 2009; Zhu et al., 2008). It has also been proved successfully in extracting As species from rice shoot, bran, husk, and root, when exactly the same procedure used for the grain was applied in these plant sections, obtaining recoveries of $94 \pm 11$ $(n=9), 91 \pm 13(n=3), 81 \pm 13(n=3)$, and $106 \pm 4 \%(n=6)$, respectively (Zhu et al., 2008). Raab et al. (2009) also demonstrated good extraction efficiency (104\%) using $1 \% \mathrm{HNO}_{3}$ with microwave extraction for rice flour CRM. For Panax notoginseng, recovery was the highest in $1 \% \mathrm{HNO}_{3}$ extract solution and the proportions of four arsenic species were stable. Moreover, a little amount of unidentified As species were detected at the same retention time, located between $\mathrm{DMA}^{\mathrm{V}}$ peak and $\mathrm{MMA}^{\mathrm{V}}$ peak (Table 1 and see Inline Supplementary Fig.S1(a)). Based on our results, $1 \% \mathrm{HNO}_{3}$ was the most suitable solution for As species extraction in CHMs.

\subsection{Arsenic speciation in Chinese Herbal Medicines}

The concentrations of arsenic species in CHMs samples collected directly from fields are shown in Table 2. Only As ${ }^{\mathrm{III}}$ and $\mathrm{As}^{\mathrm{V}}$ were detected in the extract solutions of CHMs with the roots as medicines. The concentrations ranged at $47.2-182 \mathrm{ng} / \mathrm{g}$ for $\mathrm{As}{ }^{\mathrm{III}}$ and at $1.1-264 \mathrm{ng} / \mathrm{g}$ for $\mathrm{As}^{\mathrm{V}}$. Arsenite was the predominant species in the extracts of $63 \%$ samples, accounting for $60-99 \%$ of total As. Arsenate was the main species in the remainder samples with the proportion at $66-74 \%$ (Table 2). There was quite a big difference in the dominant As species in the medicines from fields, which might depend on the growing conditions and their genetic properties.

There were no MMA or DMA found in roots of CHMs. Furthermore, arsenic species in those CHMs with shoots or flowers as medicines also followed that inorganic arsenic is predominant. Only a low level of $\mathrm{DMA}^{\mathrm{V}}(<10 \%)$ was found in the flowers of $D$. morifolium. Recent report showed that arsenic could not be methylated in planta and soil microorganisms are responsible for As methylation and $\mathrm{DMA}^{\mathrm{V}}$ in plants mainly comes from soil solution (Lomax et al., 2012). DMA ${ }^{\mathrm{V}}$ could be more slowly taken up by roots compared to inorganic As, but translocated rapidly from root to shoot (Li et al., 2009; Raab et al., 2007). This might explain that $\mathrm{DMA}^{\mathrm{V}}$ was detected in flowers of $D$. morifolium and not in roots of CHMs. 
Table 2

Speciation of arsenic in Chinese Herbal Medicines collected from fields (Means \pm SE, $n=3$ ).

\begin{tabular}{|c|c|c|c|c|c|c|c|c|}
\hline Tissues as medicine & Varieties & $\mathrm{As}^{\mathrm{III}}(\mathrm{ng} / \mathrm{g})$ & $\mathrm{As}^{\mathrm{V}}(\mathrm{ng} / \mathrm{g})$ & $\mathrm{As}^{\mathrm{III} \%}$ & $\mathrm{As}^{\mathrm{V}} \%$ & Sum of speciation $(\mathrm{ng} / \mathrm{g})^{\mathrm{b}}$ & Total As (ng/g) ${ }^{\mathrm{a}}$ & Recovery (\%) \\
\hline \multirow[t]{8}{*}{ Roots } & I. indigotica & $120.2 \pm 6.1$ & $1.1 \pm 1.1$ & $99 \pm 0.8$ & $1 \pm 0.8$ & $121.3 \pm 7.0$ & $137.4 \pm 0.0$ & $88 \pm 5.1$ \\
\hline & A. macrocephala & $181.8 \pm 6.4$ & $61.3 \pm 3.3$ & $75 \pm 0.4$ & $25 \pm 0.4$ & $243.2 \pm 9.6$ & $371.9 \pm 0.0$ & $65 \pm 2.6$ \\
\hline & S. miltiorrhiza & $84.0 \pm 3.8$ & $52.0 \pm 14.6$ & $63 \pm 8.4$ & $37 \pm 8.4$ & $136.0 \pm 11.4$ & $278.9 \pm 40.2$ & $50 \pm 3.6$ \\
\hline & S. divaricata & $47.2 \pm 39.2$ & $108.3 \pm 19.5$ & $29 \pm 15.8$ & $71 \pm 15.8$ & $174.7 \pm 25.3$ & $175.8 \pm 23.9$ & $100 \pm 9.0$ \\
\hline & A. membranaceus & $66.8 \pm 19.2$ & $39.8 \pm 10.5$ & $62 \pm 8.7$ & $38 \pm 8.7$ & $106.7 \pm 25.4$ & $140.3 \pm 9.5$ & $75 \pm 12.9$ \\
\hline & A. tataricus & $91.4 \pm 3.8$ & $264.1 \pm 29.0$ & $26 \pm 2.2$ & $74 \pm 2.2$ & $355.5 \pm 29.6$ & $525.5 \pm 103.9$ & $71 \pm 10.7$ \\
\hline & A. asphodeloides & $53.9 \pm 11.6$ & $105.8 \pm 12.4$ & $34 \pm 7.5$ & $66 \pm 7.5$ & $159.6 \pm 3.8$ & $216.2 \pm 31.6$ & $77 \pm 12.1$ \\
\hline & T. kirilowii & $79.9 \pm 10.7$ & $52.6 \pm 8.0$ & $60 \pm 0.6$ & $40 \pm 0.6$ & $132.5 \pm 18.7$ & $184.4 \pm 6.9$ & $72 \pm 10.9$ \\
\hline \multirow[t]{4}{*}{ Shoots } & S. tenuifolia & $187.3 \pm 8.4$ & $168.8 \pm 3.8$ & $53 \pm 1.4$ & $47 \pm 1.4$ & $356.1 \pm 7.9$ & $259.2 \pm 0.0$ & $137 \pm 5.0$ \\
\hline & I. indigotica & $116.7 \pm 7.0$ & $60.8 \pm 2.7$ & $66 \pm 1.6$ & $34 \pm 1.6$ & $177.4 \pm 7.4$ & $195.2 \pm 0.0$ & $91 \pm 3.8$ \\
\hline & T. kirilowii & $25.5 \pm 4.4$ & $37.2 \pm 2.6$ & $40 \pm 5.7$ & $60 \pm 5.7$ & $62.7 \pm 1.9$ & $39.1 \pm 0.0$ & $160 \pm 4.8$ \\
\hline & D. morifolium ${ }^{d}$ & $110.2 \pm 9.7$ & $303.6 \pm 60.1$ & $25 \pm 2.8$ & $67 \pm 2.8$ & $446.7 \pm 68.2$ & $351.4 \pm 72.0$ & $130 \pm 6.7$ \\
\hline
\end{tabular}

a Total As: As concentration by $\mathrm{HNO}_{3}$ digestion.

b Sum of As speciation = Sum of As species by $1 \% \mathrm{HNO}_{3}$

c Recovery $=\left(\right.$ species sum/total As) ${ }^{*} 100$.

d Contained $23.4 \mathrm{ng} / \mathrm{g}$ DMA ${ }^{\mathrm{V}}$.

Arsenic speciation in CHMs samples collected from markets or pharmacies is listed in Table 3. In general, inorganic arsenic, As ${ }^{\mathrm{III}}$ and $\mathrm{As}^{\mathrm{V}}$, was the predominant species with the proportion over 94\% like that in CHMs from fields. $\mathrm{DMA}^{\mathrm{V}}$ was only detected in roots of $A$. asphodeloides and shoots of T. kirilowii from markets at $7.3 \mathrm{ng} / \mathrm{g}$ and $15.8 \mathrm{ng} / \mathrm{g}$, respectively. The peak of un-identified As speciation was detected at retention time between $500 \mathrm{~s}$ and $600 \mathrm{~s}$, separated after $A s \mathrm{~V}$ peak in a few samples including I. indigotica, $A$. asphodeloides and D. morifolium from markets (Table 3 and see Inline Supplementary Fig.S1(b)). It would be done further analysis about this un-identified arsenic species in CHMs in the future. The $\mathrm{DMA}^{\mathrm{V}}$ percentage was less than $5 \%$ of total arsenic in these samples. Whether $\mathrm{As}{ }^{\mathrm{III}}$ and $\mathrm{As}^{\mathrm{V}}$ concentrations or total As concentrations in CHMs from markets or pharmacies (I. indigotica (shoots), A. Tataricus, A. asphodeloides, T. kirilowii (root), T. kirilowii (fruits), D. morifolium) were much higher than those in the same CHMs collected directly from fields (Tables 2 and 3), accounting for 1.9-30 times. This indicated that arsenic accumulation and speciation in these CHMs from markets have been impacted during dryness, storage, transport and manufacturing processes of herbs. Moreover, the highest mean concentrations of $\mathrm{As}^{\mathrm{III}}, \mathrm{As}^{\mathrm{V}}$ and total As were $2443 \mathrm{ng} / \mathrm{g}, 1560 \mathrm{ng} / \mathrm{g}$ and $3790 \mathrm{ng} / \mathrm{g}$ in flowers of D. morifolium from markets and pharmacies, which is related to the process of sulfur fumigation of the flowers of $D$. morifolium. In general, sulfur fumigation is commonly used to reduce the damage of insects and fungus on herbs, especially during processes of the dryness and storage of Chrysanthemum flowers. Sulfur powder, from natural stone with sulfur, is normally combined with a little amount of arsenic and produces the gas with arsenic contaminating Chrysanthemum flowers during fumigation. Although State Food and Drug Administration in China issued the regulation to ban using sulfur power to fumigate CHMs in 2004 for harmful gases emission, human health assessments of arsenic accumulation and speciation in Chrysanthemum flowers from the markets should do further investigation to make this point clear.

The levels of inorganic As in edible plants are closely related to the toxicity of arsenic to human health (Schoof et al., 1999; Zavala et al., 2008). When data from all of field collected samples plotted together, a striking pattern can be observed that the concentration of inorganic As increased with increasing total As $(r=0.720, P<0.01)$ (Fig. 1a). The same pattern also appeared in data plot between inorganic As and total As in CHMs from markets or pharmacies $(r=0.987, P<0.01)$ (Fig.1b). This relationship between inorganic As and total As was also reported in rice grain samples by Xu et al. (2008) and Zavala et al. (2008).

The recoveries of arsenic species varied from $48 \%$ to $160 \%$ for different CHMs samples from fields and markets or pharmacies (Tables 2 and 3). The mean recovery of As species from shoot of T. kirilowii was $158 \%$ and the recovery from root of S. miltiorrhiza was around $50 \%$. The variation of recoveries for arsenic species has been reported in rice samples by Heitkemper et al. (2001) from 31 to $75 \%$ and in bran and flour of wheat by Zhao et al. (2010) from $57 \%$

Table 3

Speciation of arsenic in Chinese Herbal Medicines collected from markets or pharmacies (Means $\pm \mathrm{SE}, n=3$ ).

\begin{tabular}{|c|c|c|c|c|c|c|c|c|c|}
\hline $\begin{array}{l}\text { Tissues as } \\
\text { medicines }\end{array}$ & Varieties & $\mathrm{As}^{\mathrm{III}}(\mathrm{ng} / \mathrm{g})$ & $\mathrm{As}^{\mathrm{V}}(\mathrm{ng} / \mathrm{g})$ & $\mathrm{As}^{\mathrm{III}} \%$ & $\mathrm{As}^{\mathrm{V}} \%$ & $\begin{array}{l}\text { Sum of speciation } \\
(\mathrm{ng} / \mathrm{g})^{\mathrm{a}}\end{array}$ & Total As (ng/g) & Recovery (\%) & $\begin{array}{l}\text { Un-identified As } \\
\text { species (ng/g) }\end{array}$ \\
\hline \multirow[t]{8}{*}{ Roots } & I. indigotica & $90.4 \pm 7.5$ & $15.5 \pm 5.90$ & $86 \pm 5.6$ & $14 \pm 5.6$ & $106 \pm 6.8$ & $205 \pm 19.7$ & $53 \pm 8.7$ & \\
\hline & A. macrocephala & $178.3 \pm 9.0$ & $32.0 \pm 22.5$ & $86 \pm 8.6$ & $14 \pm 8.6$ & $210 \pm 22.8$ & $213 \pm 28.6$ & $100 \pm 7.6$ & \\
\hline & S. miltiorrhiza & $99.7 \pm 18.7$ & $49.1 \pm 23.0$ & $70 \pm 5.6$ & $30 \pm 5.6$ & $149 \pm 41.8$ & $322 \pm 112$ & $48 \pm 3.0$ & \\
\hline & S. divaricata & $60.4 \pm 2.0$ & $202.7 \pm 19.7$ & $23 \pm 2.0$ & $77 \pm 2.0$ & $263 \pm 18.9$ & $268 \pm 17.6$ & $98 \pm 2.3$ & \\
\hline & A. membranaceus & $49.1 \pm 7.0$ & $82.0 \pm 13.6$ & $38 \pm 2.6$ & $62 \pm 2.6$ & $131 \pm 19.1$ & $247 \pm 33.1$ & $53 \pm 2.1$ & \\
\hline & A. tataricus & $342.0 \pm 218$ & $505.4 \pm 187$ & $35 \pm 8.1$ & $65 \pm 8.1$ & $847 \pm 403$ & $1224 \pm 549$ & $69 \pm 7.3$ & \\
\hline & A. asphodeloides ${ }^{e}$ & $1217.0 \pm 693$ & $700.5 \pm 99.5$ & $58 \pm 6.9$ & $37 \pm 6.9$ & $1331 \pm 744$ & $1519 \pm 896$ & $90 \pm 3.6$ & \\
\hline & T. kirilowii & $2393.0 \pm 508$ & $571.8 \pm 426$ & $71 \pm 5.9$ & $25 \pm 5.9$ & $2353 \pm 1234$ & $2349 \pm 1249$ & $95 \pm 9.3$ & $195 \pm 11.9$ \\
\hline \multirow[t]{4}{*}{ Shoots } & S. tenuifolia & $135.8 \pm 16.3$ & $204.7 \pm 46.0$ & $41 \pm 7.7$ & $59 \pm 7.7$ & $340 \pm 29.9$ & $341 \pm 15.1$ & $99 \pm 4.4$ & \\
\hline & I. indigotica & $150.8 \pm 36.7$ & $258.6 \pm 55.9$ & $35 \pm 0.9$ & $61 \pm 0.9$ & $430 \pm 106$ & $485 \pm 113$ & $88 \pm 9.0$ & $31.5 \pm 27.8$ \\
\hline & T. kirilowii & $95.3 \pm 17.3$ & $90.6 \pm 31.0$ & $51 \pm 6.6$ & $43 \pm 6.6$ & $202 \pm 55.3$ & $127 \pm 31.0$ & $155 \pm 7.1$ & \\
\hline & D. morifolium & $2442.7 \pm 730$ & $1559.8 \pm 501$ & $58 \pm 4.6$ & $39 \pm 4.6$ & $4103 \pm 1175$ & $3790 \pm 938$ & $103 \pm 6.8$ & $101 \pm 37.7$ \\
\hline
\end{tabular}

\footnotetext{
${ }^{\text {a }}$ Species sum $=\mathrm{As}^{\mathrm{III}}+\mathrm{As}^{\mathrm{V}}+$ un-identified As species $+\mathrm{DMA}^{\mathrm{V}}$.

b Total As: As concentration $\mathrm{HNO}_{3}$ digestion.

${ }^{c}$ Recovery $=$ (species sum/total As)*100.

d contained unidentified As species.

e contained $7.3 \mathrm{ng} / \mathrm{g} \mathrm{DMA} \mathrm{V}^{\mathrm{V}}$ and $15.8 \mathrm{ng} / \mathrm{g}$, respectively.
} 

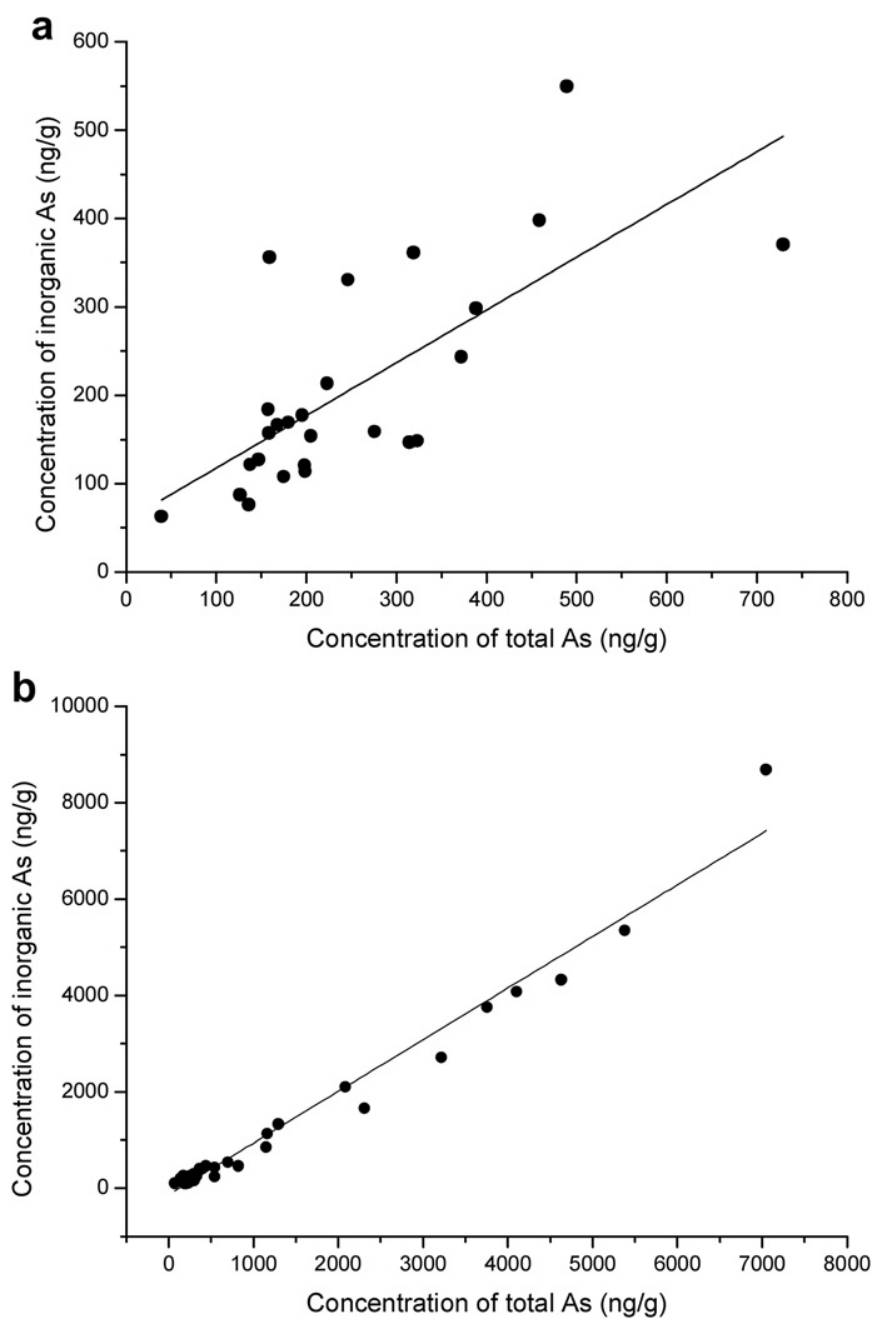

Fig. 1. Relationship between the concentrations of inorganic As and total As in CHMs (a: samples collected directly from fields, $r=0.720, P<0.01, n=26$; b: samples collected from markets or pharmacies, $r=0.987, P<0.01, n=39$ ).

to $218 \%$ using the same extract solution $\left(1 \% \mathrm{HNO}_{3}\right)$ as that in this study. The former article indicated that it was difficult to explain the large differences in extraction efficiency and recovery among different samples. Zhao et al. (2010) gave the explanation for anomalously high recovery of $218 \%$ in white flour of wheat that total As concentration in this sample was very low at $21 \mathrm{ng} / \mathrm{g}$, compared with 50-205 ng/g in other samples. Our results also followed this explanation (Tables 2 and 3 ).

For As species determination in the samples from this survey, the percentages of methylated As were no more than $10 \%$ for all CHMs growing in Anguo area of Hebei Province. However, the proportion of methylated arsenic in the Panax notoginseng sample was $31 \%$ of total As using the same method. In addition, unidentified As speciation in Panax notoginseng differed from that in other CHMs samples. The diversity of As speciation and its proportion between samples may be attributed to the different herbal varieties and growth regions relevant to Panax notoginseng growing in Yunnan province and 12 species of CHMs growing in Hebei province. The soil properties and climate conditions are totally different between these two areas and lead to differences in methylated As levels among CHMs. Williams et al. (2006, 2005) also investigated arsenic speciation in different rice varieties from different locations around the globe to explore the contributions of rice to arsenic exposure and demonstrated the predominant species detected in rice from European, Bangladeshi, and Indian being inorganic arsenic but DMA being a main component in rice from the USA. Although Zavala et al. (2008) indicated that genetic differences lead to arsenic speciation variation finally, processing and cultivating conditions are also reasons for the diversity of arsenic speciation in edible plants (Meharg et al., 2008; Smith et al., 2008).

\subsection{Human health implication for inorganic As}

The predominant arsenic species in samples of CHMs using $1 \%$ $\mathrm{HNO}_{3}$ extraction was inorganic As. Inorganic arsenic concentrations ranged from 62.7 to $550 \mathrm{ng} / \mathrm{g}(n=26)$ with a mean of $208 \mathrm{ng} / \mathrm{g}$ in CHMs from fields (Fig.1a) and ranged from 93.5 to $8683 \mathrm{ng} / \mathrm{g}$ $(n=39)$ with a mean of $1092 \mathrm{ng} / \mathrm{g}$ in CHMs from markets or pharmacies (Fig.1b). The Chinese Maximum Contaminant Levels (MCLs) of inorganic As in foods was presented in 2005, such as rice (150 ng/g), wheat flour (100 ng/g), non-staple cereals (200 ng/g) and vegetables (50 ng/g)(China Food Standard Agency, 2005), not including the maximum limit of inorganic As level for CHMs. If the MCL of inorganic As in non-staple cereal crops (200 ng/g) was referred in this study for the similar growing conditions to discussion the health risk assessment of inorganic arsenic in CHMs, about $65 \%$ of the CHMs from field and $25 \%$ of the CHMs from markets or pharmacies would be legal for sale in China; If compared to MCL of inorganic As in vegetables (50 ng/g), inorganic As concentrations in all of CHMs exceeded this limitation.

To estimate the daily intake of arsenic from CHMs, the dose ingested should be taken into account. In accordance with the conservative principle, the maximum dose of each CHMs prescribed by the Chinese Pharmacopoeia was selected in the risk calculation (for example $9 \mathrm{~g} / \mathrm{d}$ was selected as the dose in the risk calculation when $4.5-9 \mathrm{~g} / \mathrm{d}$ was recommended for $S$. divaricata in Chinese Pharmacopoeia) (Chinese Pharmacopoeia Commission, 2005). If the inorganic As concentration in CHMs is $200 \mathrm{ng} / \mathrm{g}$ (MCL) and consumption of $30 \mathrm{~g}$ CHMs by a $60 \mathrm{~kg}$ person daily, the proportion of the daily intake value to the ADI $(126 \mu \mathrm{g})$ from FAO/ WHO is $4.76 \%$, which can be explained that a potential risk will exist if the proportion value of daily intake for inorganic As in CHMs is higher than $4.76 \%$. So, the percentage of inorganic As in CHMs to ADI was calculated and shown in the Fig. 2. According to our data, daily contribution of inorganic arsenic in all samples from field

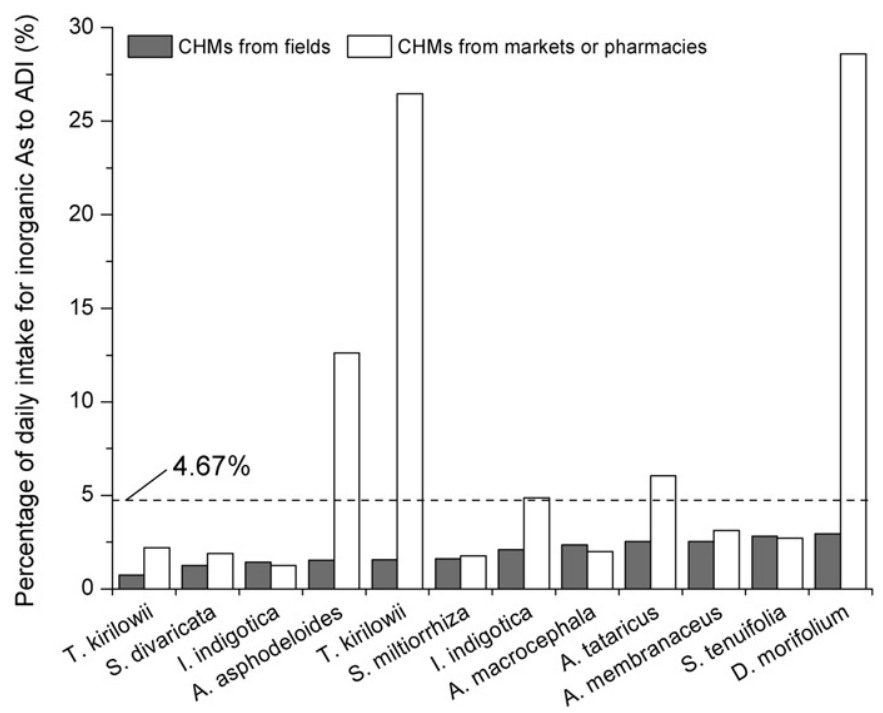

Fig. 2. Comparison of percentages of dietary exposure for inorganic arsenic inducing by CHMs collected from fields and from markets or pharmacies. 
ranged from $0.94 \mu \mathrm{g}$ to $4.95 \mu \mathrm{g}$, and counting for $0.75-2.83 \%$ of ADI. The range of daily intake of inorganic arsenic in all samples from markets or pharmacies was from $1.29 \mu \mathrm{g}$ to $78.2 \mu \mathrm{g}$ with the risk values of $1.02-62.0 \%$. The comparison of percentages of daily intake for inorganic arsenic in CHMs from fields and markets or pharmacies was shown in Fig.2. For the CHMs of I. indigotica (shoots), A. Tataricus, A. asphodeloides, T. kirilowii (root), T. kirilowii (fruits), and $D$. morifolium, the proportions of inorganic As daily intake to $\mathrm{ADI}$ in CHMs from markets or pharmacies were much higher than that from fields.

According to the highest boundary of estimated inorganic As exposure from food $(1.22 \mu \mathrm{g} / \mathrm{kg}$ b.w. per day) published by EFSA (2009), ADI of inorganic As for one person with $60 \mathrm{~kg}$ bodyweight will be $73.2 \mu \mathrm{g}$, which is only $58.1 \%$ of ADI $(126 \mu \mathrm{g})$ from FAO/WTO. If ADI $(73.2 \mu \mathrm{g})$ is adapted in this health risk assessment of inorganic As in CHMs, the contribution of daily intake of inorganic As from all of CHMs to health risk will increase significantly.

\section{Conclusion}

Inorganic arsenic was the predominant species detected in all of CHMs samples with the proportion of $94-100 \%$. Inorganic arsenic levels in CHMs from fields and markets or pharmacies ranged from 62.7 to $550 \mathrm{ng} / \mathrm{g}$ and 94 to $8683 \mathrm{ng} / \mathrm{g}$, respectively. The highest concentration of inorganic arsenic was found in the flowers of $D$. morifolium from pharmacies. The study provides useful information for a better understanding of the distribution of arsenic species in Chinese Herbal Medicines. In addition, the risk of inorganic As in CHMs from markets or pharmacies to human health should be paid more attention further.

\section{Acknowledgments}

This study was supported by the Natural Science Foundation of Hebei Province (C2009000590) and the New Century Excellent Talents of Hebei Province (CPRC028). We sincerely thank Dr. Ben Simon for improving this manuscript in language.

\section{Appendix A. Supplementary data}

Supplementary data related to this article can be found at http:// dx.doi.org/10.1016/j.envpol.2012.09.009

\section{References}

Abedin, M.J., Cresser, M.S., Meharg, A.A., Feldmann, J., Cotter-Howells, J., 2002. Arsenic accumulation and metabolism in rice (Oryza sativa L.). Environmental Science and Technology 36, 962-968.

Ackerman, A.H., Creed, P.A., Parks, A.N., Fricke, M.W., Schwegel, C.A., Creed, J.T., Heitkemper, D.T., 2005. Comparison of a chemical and enzymatic extraction of arsenic from rice and an assessment of the arsenic absorption from contaminated water by cooked rice. Environmental Science and Technology 39, 52415246.

Akerele, O., 1993. Nature's medicinal bounty: don't throw it away. World Health Forum 14, 390-395.

Au, A.P., Reddy, M.B., 2000. Caco-2 cells can be used to assess human iron bioavailability from a semipurified meal. Journal of Nutrition 130,1329-1334.

Chan, K., 2003. Some aspects of toxic contaminants in herbal medicines. Chemosphere 52, 1361-1371.

China Food Standard Agency(CFSA), 2005. Maximum Levels of Contaminants in Foods. Beijing, GB2762.

Chinese Pharmacopoeia Commission(CPC), 2005. Chinese Pharmacopoeia. Beijing.

Cooper, K., Noller, B., Connell, D., Yu, J., Sadler, R., Olszowy, H., Golding, G., Tinggi, U., Moore, M.R., Myers, S.P., 2007. Public health risks from heavy metals and metalloids present in traditional Chinese medicines. Journal of Toxicology and Environmental Health Part A 70, 1694-1699.

European Food Safety Authority (EFSA) Panel on Contaminants in the Food Chain (CONTAM), 2009. Scientific opinion on arsenic in food. EFSA Journal 7, 1351.

FAO/WHO (Food and Agriculture Organization/World Health Organization), 1993. Evaluation of Certain Food Additives and Contaminants. Technical Report Series 837. Geneva, Switzerland.
Heitkemper, D.T., Vela, N.P., Stewart, K.R., Westphal, C.S., 2001. Determination of total and speciated arsenic in rice by ion chromatography and inductively coupled plasma mass spectrometry. Journal of Analytical Atomic Spectrometry $16,299-306$

IARC (International Agency for Research on Cancer), 1973. Arsenic and Inorganic Arsenic Compounds. In: IARC Monographs on the Evaluation of Carcinogenic Risk of Chemicals to Man Vol. 2: Some Inorganic and Organometallic Compounds. IARC, Lyon. 48-73.

Koch, I., Sylvester, S., Lai, V.W.M., Owen, A., Reimer, KJ., Cullen, W.R., 2007. Bioaccessibility and excretion of arsenic in Niu Huang Jie Du Pian pills. Toxicology and Applied Pharmacology 222, 357-364.

Koh, H.L., Woo, S., 2000. Chinese proprietary medicine in Singapore: regulatory control of toxic heavy metals and undeclared drugs. Drug Safety 23, 351-362.

Li, R.Y., Stroud, J.L., Ma, J.F., McGrath, S.P., Zhao, F.J., 2009. Mitigation of arsenic accumulation in rice with water management and silicon fertilization. Environmental Science and Technology 43, 3778-3783.

Liang, W., Lin, S., Yen, K., Yang, L., 1998. Metal element analysis of commercia Chinese herbal medicines. Taiwan Kexue 51, 37-56.

Liu, W.J., Zhu, Y.G., Hu, Y., Williams, P.N., Gault, A.G., Meharg, A.A., Charnock, J.M., Smith, F., 2006. Arsenic sequestration in iron plaque, its accumulation and speciation in mature rice plants (Oryza sativa L.). Environmental Science and Technology 40, 5730-5736.

Liu, X.J., Liu, W.J., Lin, A.J., Liu, Y.X., 2010a. Survey of arsenic concentrations in Chinese herbal medicines (CHMs) and preliminary risk assessment of As in CHMs on human health. Environmental Science 31, 205-211 (in Chinese)

Liu, X.J., Lin, A.J., Sun, G.X., Liu, Y.X., Liu, W.J., 2010b. Arsenic speciation in edible plants: a review. Chinese Journal of Applied Ecology 21, 1883-1891 (in Chinese).

Lomax, C., Liu, W.J., Wu, L.Y., Xue, K., Xiong, J.B., Zhou, J.Z., McGrath, S.P., Meharg, A.A., Miller, A.J., Zhao, F.J., 2012. Methylated arsenic species in plants originate from soil microorganisms. New Phytologist 193, 665-672.

Marin, A.R., Masscheleyn, P.H., Patrick, W.H., 1992. The influence of chemical form and concentration of arsenic on rice growth and tissue arsenic concentration. Plant and Soil 139, 175-183.

Meharg, A.A., Lombi, E., Williams, P.N., Scheckel, K.G., Feldmann, J., Raab, A., Zhu, Y., Islam, R., 2008. Speciation and localization of arsenic in white and brown rice grains. Environmental Science and Technology 42, 1051-1057.

Muñoz, O., Diaz, O.P., Leyton, I., Nuñez, N., Devesa, V., Súñer, M.A., Vélez, D. Montoro, R., 2002. Vegetables collected in the cultivated Andean area of northern Chile: total and inorganic arsenic contents in raw vegetables. Journal of Agricultural and Food Chemisty 50, 642-647.

NRC (National Research Council), 2001. Arsenic in Drinking Water: 2001 Update. National Academy Press, Washington, DC.

Raab, A., Williams, P.N., Meharg, A., Feldmann, J., 2007. Uptake and translocation of inorganic and methylated arsenic species by plants. Environmental Chemistry 4, 197-203.

Raab, A., Baskaran, C., Feldmann, J., Meharg, A.A., 2009. Cooking rice in a high water to rice ratio reduces inorganic arsenic content. Journal of Environmental Monitoring 11, 41-44.

Schoof, R.A., Yost, L.J., Eickhoff, J., Crecelius, E.A., Cragin, D.W., Meacher, D.M., Menzel, D.B., 1999. A market basket survey of inorganic arsenic in food. Food and Chemical Toxicology 37, 839-846.

Smith, E., Juhasz, A.L., Weber, J., Naidu, R., 2008. Arsenic uptake and speciation in rice plants grown under greenhouse conditions with arsenic contaminated irrigation water. Science of the Total Environment 392, 277-283.

Smith, N.M., Lee, R., Heitkemper, D.T., DeNicola Cafferky, K., Haque, A. Henderson, A.K., 2006. Inorganic arsenic in cooked rice and vegetables from Bangladeshi households. Science of the Total Environment 370, 294-301.

Tsuji, J.S., Yost, L.J., Barraj, L.M., Scrafford, C.G., Mink, P.J., 2007. Use of background inorganic arsenic exposures to provide perspective on risk assessment results. Regulatory Toxicology and Pharmacology 48, 59-68.

Vela, N.P., Heitkemper, D.T., 2004. Total arsenic determination and speciation in infant food products by ion chromatography-inductively coupled plasma-mass spectrometry. Journal of AOAC International 87, 244-252.

Williams, P.N., Price, A.H., Raab, A., Hossain, S.A., Feldmann, J., Meharg, A.A., 2005 Variation in arsenic speciation and concentration in paddy rice related to dietary exposure. Environmental Science and Technology 39, 5531-5540.

Williams, P.N. Islam, M.R. Adomako, E.E., Raab, A. Hossain, S.A. Zhu, Y.G. Feldmann, J., Meharg, A.A., 2006. Increase in rice grain arsenic for regions of Bangladesh irrigating paddies with elevated arsenic in groundwaters. Environmental Science and Technology 40, 4903-4908.

Xu, X.Y., McGrath, S.P., Meharg, A.A., Zhao, F.J., 2008. Growing rice aerobically markedly decreases arsenic accumulation. Environmental Science and Technology 42, 5574-5579.

Zavala, Y.J., Gerads, R., Gürleyük, H., Duxbury, J.M., 2008. Arsenic in rice: II. Arsenic speciation in USA grain and implications for human health. Environmental Science and Technology 42, 3861-3866.

Zhao, FJ. Stroud, J.L., Eagling T., Dunham, S.J., McGrath, S.P., Shewry, P.R, 2010. Accumulation, distribution, and speciation of arsenic in wheat grain. Environmental Science and Technology 44, 5464-5468.

Zhu, Y.G., Sun, G.X., Lei, M., Teng, M., Liu, Y.X., Chen, N.C., Wang, L.H., Carey, A.M. Deacon, C., Raab, A., Meharg, A.A., Williams, P.N., 2008. High percentage inorganic arsenic content of mining impacted and nonimpacted Chinese rice. Environmental Science and Technology 42, 5008-5013. 